\title{
On Anaphors Linked to Names Used Metaphorically
}

\author{
Eros Corazza* - Christopher Genovesi**
}

Received: 3 September 2020 / Accepted: 5 December 2020

Abstract: In their 2018 paper "On the Metaphoric Use of (Fictional) Proper Names", Corazza \& Genovesi explored what speakers do when they utter a fictional name in a metaphorical way to refer to actual individuals. The example given was "Odysseus returned home" referring to their friend Bill, who had returned after a long and hectic journey. With such an example in mind, Corazza \& Genovesi claimed that speakers produce a metaphorical utterance where properties of Odysseus are mapped onto the referent that the speaker intends so that they refer to that person. That is to say, the name "Odysseus" somewhat ceases to be a proper name, and instead becomes something akin to a Donnellan's referential use of descriptions, i.e. a description that successfully picks out an object of discourse even if the latter does not satisfy the descriptive content conveyed by the description. In our example Bill does not satisfy the property of being called "Odysseus". In this paper, we connect the previous work by Corazza \& Genovesi's with anaphora, in particular with the use of anaphoric definite descriptions linked to a metaphorical use of a proper name. With fictional proper names in mind, we are interested

* University of the Basque Country and Carleton University

(iD) https://orcid.org/0000-0001-8074-7777

- The University of the Basque Country UPV-EHU, Donostia, Spain.

$\bowtie$ eros.corazza@carleton.ca

** University of the Basque Country

https://orcid.org/0000-0001-8890-8336

The University of the Basque Country UPV-EHU, Donostia, Spain.

$\triangle$ genovesi.c@gmail.com

(C) The Author. Journal compilation (C) The Editorial Board, Organon F.

This article is distributed under the terms of the Creative Commons Attribution-NonCommercial 4.0 International Public License (CC BY-NC 4.0). 
in cases where speakers anaphorically refer to the actual referent. For example, we are interested in utterances of the sort "Odysseus returned home, he1 is hungry" or "Odysseus1 returned home, the/that brave soldier1 is hungry", where "Odysseus" is metaphorically used to refer to the actual person, Bill, the individual the speaker has in mind. Such sentences leave us wondering how the anaphoric pronoun or description simultaneously carries the content from the fictional subject, and refers to Bill. On a cursory analysis, anaphora forces the properties attributed to the actual referent (e.g., Bill) into the background, like pragmatic presupposition. In the cases of anaphoric complex demonstratives and definite descriptions, the speaker emphasizes, or makes salient the further implications shared between the fictional character (e.g., Odysseus) and the actual referent (e.g., Bill; and that Bill, like Odysseus, had a harrowing journey).

Keywords: Proper names, metaphors, descriptions; anaphors, antilogophoric pronouns.

\section{Introduction}

Proper names and metaphors have been discussed independently at great length in philosophy and linguistics, and much more recently in cognitively oriented disciplines such as psychology. However, there isn't much discussion about the use of proper names in metaphorical utterances. ${ }^{1}$ In fact, many discussions concerning metaphor are limited to decontextualized noun-noun predicative types, conventionally captured by the formula: $A$ is (a) $B$ (e.g., "Man is a wolf"). Because metaphors can occur in a variety of linguistic expressions, it is important that theorists of metaphor, and theorists of language more broadly, examine the variety of types of metaphor to generate a tractable theory. The reason is that theories focused on decontextualized utterances of the $A$ is (a) $B$ type may lack the generalizability to accommodate metaphors in a wider linguistic context (e.g., embedded metaphors, anaphora, and extended metaphors such as literary conceits). By way of a general analysis, this paper raises some issues concerning

1 For some discussion, see Cacciari \& Glucksberg (1994), Glucksberg \& Keysar (1990), Leezenberg (2001), and Ritchie (2013). 
metaphorical proper names (MPNs) in combination with anaphoric descriptions that can serve as the topic for further investigations concerning the behaviour of metaphors in general, and MPNs in particular.

First, in connection with previous work on the topic (e.g., Corazza \& Genovesi, 2018) we claim that the function of a MPN somewhat ceases to be a proper name, and instead becomes something akin to the referential use of descriptions à la Donnellan, i.e. a description that successfully picks out an object of discourse even if the latter does not fully satisfy the descriptive content of the description (details below). Secondly, we build on these previous observations by connecting them to anaphoric descriptions. For example, we are interested in utterances of the sort "Odysseus returned

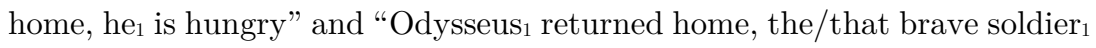
is hungry", where "Odysseus" is metaphorically used to pick out Bill- the individual the speaker has in mind - and the anaphoric clause is linked to the intended referent. Note that in our paradigm case "Odysseus returned home", the fictional name "Odysseus" does not function like a Fregean case (i.e., like "Tully" and "Cicero" referring to one and the same orator) where the auditor is simply unaware that Odysseus is Bill's alias. Rather, the intended referent, Bill, is determined in part by the auditor recognizing what the speaker intends by the metaphorical use of the (fictional) proper name, and the intended referent updates the shared beliefs of the speakers so that the anaphoric clause is felicitous.

The use of MPNs leave us wondering how anaphoric pronouns and descriptions simultaneously carry the content from the (fictional) subject, and refer to the actual referent. The essay is broken down as follows: In section 1 , we define what we mean by MPN. In section 2, we offer a cursory analysis on anti-logophoricity which we maintain can help us understanding MPNs and anaphoric clauses. This leads us to consider how the properties attributed to the actual referent of an MPN (e.g., Bill) are forced into the background, like pragmatic presupposition (section 4). In the cases of anaphoric complex demonstratives and definite descriptions, the speaker can insist on, or make salient, further features shared between the fictional character (e.g., Odysseus) and the actual referent (e.g., Bill; and that Bill, like the mythical Odysseus, should want to eat a full meal after such a long journey, etc.). Section 5 concludes by briefly discussing avenues for further research. 


\section{What is an MPN?}

In defining what metaphor is, theorists often speak of the relationship between conceptually distinct entities, where the conceptual entity described as the "topic" or "target" is understood by some other conceptually distinct entity described as the "base", "target" or "source" (see Wee, 2006). We take MPNs to be utterances where the referent of the proper name functions as the source. In this paper, we follow Genovesi (2018), in speaking of "source" and "target" characterizations. So, for example, an utterance such as "John is a rock", although metaphorical, does not qualify as an MPN. Crudely, it describes the individual John as being physically strong, and perhaps capable of taking some relevant high degree of physical punishment. Here, John is the target, and the source is rock. By contrast, MPNs exploit the value of proper names as the source in characterizing some target.

In our paradigm case "Odysseus returned home", "Odysseus" is an MPN expression because the name is used to characterize the intended source, Bill. Another example of an MPN expression is the following said of Matthew Stafford (Quarter back for the Detroit Lions American football club): "Shakespeare has made yet another wonderful play!" One thing to note is

2 We believe that both examples differ from metonymic expressions. Theoretically, metonymy involves drawing a contiguity between two entities, whereas metaphor involves drawing a resemblance between two distinct conceptual entities. In both examples above, we a have a resemblance established between classes of people who have been away, and mythic heroes who have been fighting for their homecoming. In the second example, we have the resemblance between classes of people who play football exceptionally well, and those who write exceptionally well. Metonymy, on the other hand, involves the use of establishing a relationship within the same conceptual domain (e.g., "There was no comment from the White House" where the underlined term stands for or provides access to the sub-domain: the American government. Similarly, in "He is reading Shakespeare" the source domain SHAKESPEARE stands for the subdomain SHAKESPEARE'S WRITINGS). Standard types of metonymic mappings are, part for whole, producer for product, place for institution, object used for user. Empirically, recent work on metaphor and metonymy suggests a difference in processing strategies where metonymy is more closely related to literal speech than metaphor (see, e.g., Bambini et al. 2013). 
that an MPN is intended to invoke some property or subset of properties that will only makes sense if the auditor or audience has some (basic) appreciation of the legend of Odysseus and his travails. In this way, the meaning must be inferred locally. That is to say, it is important that the audience have some knowledge that Odysseus was the hero of Homer's epic, the Odyssey, most famous for his homecoming which lasted ten eventful years. So too, perhaps, is knowledge of the fact that Odysseus was not recognized by anyone except his dog Argos, that he is the husband of Penelope, and that he is the legendary king of Ithaca. In this case, it is not simply the conventional meanings of the terms and their mode of combination, but the "substantive and wide-ranging presuppositions (both real and mutually pretended) about the referents of the relevant expressions" (Camp, 2009, p. $265)$ that aid in shaping the metaphorical interpretation of the MPN expression (we turn to this in Section 4 ). ${ }^{3}$

In what follows, we investigate how MPNs can set up discourse referents and contribute to a larger conversational context. Specifically, we focus on the way anaphoric pronouns are linked to names used metaphorically. Consider the following two paradigm cases of our investigation below:

(1) Odysseusı returned home, he $e_{1}$ is hungry

(2) Odysseus 1 returned home, [the brave soldier $]_{1}$ is hungry ${ }^{4}$

If we understand (1) literally, it comes to mean that the anaphoric "he", if co-indexed with "Odysseus", is co-referential with it. It picks up Odysseus as its referent, and the anaphoric clause inherits the semantic value of the name that it is linked to and co-indexed with. However, if we treat the use of "Odysseus" in (1) or (2) to be metaphorical - the motivation for so doing

3 Note that our example MPNs are used referentially (that is as a label for an entity). MPNs can also be used predicatively (as a description that an entity may satisfy to some degree, or not satisfy at all). This is not a problem for our view, since we understand that in both cases, the auditor must narrow the search for referable things or properties expressed by an utterance. For discussion, see Wee $(2006,357-$ 58). In general, the use of MPNs is motivated by some pragmatically intended salient property or properties.

4 Though we will concentrate on descriptions used anaphorically, we think the same story could be used to analyze complex demonstratives used anaphorically, like e.g.: "Odysseus 1 returned home, [that brave soldier] $]_{1}$ is hungry". 
arising from one or a combination of the following: Bill's long absence; his arduous journey abroad; that we (like the faithful Argos) were the only members of the friend group able to recognize Bill after his long absence, etc. - with the use of the name to refer to our friend Bill, then the semantic value of the anaphoric "he" cannot be Odysseus; it must be Bill. How is this possible?

\section{Anti-logophoriciti}

In order to understand this phenomenon, we think it might be instructive to look at how descriptions can be linked, and co-referential, with their antecedent. Consider so-called anti-logophoric pronouns ${ }^{5}$ like "the dumb racist" in (3):

(3) Donald Trump 1 returned home, [the dumb racist $]_{1}$ is hungry ${ }^{6}$

In (3) the speaker picks up Donald Trump as the object of discourse and says that he returned home and he is hungry. On top of that, the speaker further attributes to him the property of being a dumb racist. For sure, Donald Trump does not consider himself to be dumb (quite the contrary, as his tweets allege), let alone a racist. In (3) it is the narrator that characterizes

5 Logophoricity is a term first introduced by Hagège (1974) in studies of African languages. A logophoric pronoun always appears in an attitude ascription or oratio obliqua construal. It is an anaphoric pronoun that, on top of being co-referential with the term it is co-indexed with, it attributes to the referent of the antecedent a thought s/he would express. For instance, "she (herself)" in "Mary thinks that she (herself) is bright" can be considered as a logophoric pronoun insofar as it attributes to Mary a thought she would express by using the pronoun "I". On the contrary, an anti-logophoric pronoun is an anaphoric pronoun that attributes to the referent of the term it is co-indexed with a property the latter would not attribute to him/herself, let alone accept it as a correct characterization of him/herself (see Corazza 2005; Dubinsky \& Hamilton 1998).

${ }_{6}$ In no way do the authors intend to insult or undermine the former president of the USA. We use "Donald Trump" merely as an example to illustrate the phenomenon we are trying to highlight. The example was taken from a personal conversation, and we have since let that friend go.

Organon F 28 (1) 2021: 253-268 
Donald Trump as a dumb racist. This epithet is something that transcends the main purpose of the utterance, i.e. to claim that Donald Trump returned home and he is hungry.

To highlight this, consider that this sentence is voiced by one of Trump's butler who, needless to say, does not hold his boss in high esteem. Our butler's main communicative intention is to inform his collaborators that Trump arrived and he is hungry, and perhaps to communicate the conversational implicature that they should go fetch his favourite cheeseburger. Yet, the speaker, on top of saying that Donald Trump returned home and that he is hungry, also characterizes Donald Trump to be a dumb racist. One way to understand (3) is to argue that the speaker expresses three propositions to which he is committed:

(3) a. That Donald Trump returned home

(3) b. That Donald Trump is hungry

(3) c. That Donald Trump is a dumb racist

All three propositions could be true, all false, some true and others false. Donald Trump may have returned home, but he may not be hungry. He may not have returned and be hungry. He may have returned home and be hungry, but not be a dumb racist. He may be a dumb racist who is not home yet, etc.

Whether (3) is false/true if all the propositions are true/false is not a matter we will be concerned with here. Our aim is much more mundane. We want to figure out how descriptions (or complex demonstratives) work when anaphorically linked to names used metaphorically. In due course, we explain how this analysis can be applied to give us understanding of MPN expressions like (1) and (2) with the proper name "Odysseus" used metaphorically to select Bill as the object of discourse in connection with the anaphoric clause.

\section{Attributive anaphors}

Following Corazza (2005), we want to treat anaphors found in utterances such as (1) and (2) as attributive anaphors. However, although there are some similarities between these two cases, we would like to highlight 
their differences. One of the major differences between (1) and (2) is the following: In the first example, we know that in our discourse situation the anaphoric pronoun "he" refers to Bill, the subject raised to salience by the metaphorical use of "Odysseus", and not to Odysseus, the fictional character. The anaphoric pronoun marks the gender of the referent of the utterance. According to our introspective judgements, we believe this to be obligatory. We offer examples where there is gender disagreement between the MPN, and the gender of the person the speaker is referring to. For example, assume that Bill has a very close friend, John, who has been eagerly anticipating Bill's return. Later at the pub, in speaking about John, Mary utters:

(4) Penelope ${ }_{1}{ }^{7}$ is at the bar, and he,'s waiting for Odysseus/Bill

An auditor in the know would understand that in this situation "Penelope" is used to refer to John, as stressed by the anaphoric pronoun "he" motivated by John's anticipating and longing to have his friend back. However, consider the same utterance where the speaker uses an alternate pronoun, and within a speech report. In such a communicative situation it seems strange, if not infelicitous, to utter the following:

(5) ? Penelope 1 is at the bar, and she1's waiting for Odysseus $/$ Bill $^{8}$

(5) ? a. Chris said that Penelope is at the bar, and she's waiting for Odysseus/Bill

when referring to our mutual friend, John. Unless, of course, the speaker uses "she" in a figurative (i.e., sarcastic) way to, for instance, deride John as being too feminine. ${ }^{9}$

If we were uttering (4) literally, then we are constrained by the common practice to preserve gender agreement between the name and the anaphoric

7 According to the Homeric Epic, Penelope is Odysseus' wife. After ten years spent fighting the Trojan War, Odysseus spent another ten years finding his way back to his wife and his kingdom of Ithaca. All the while, Penelope had eagerly anticipated his return.

8 It may be permissible to use the third person plural "they" which has more recently been used as a gender-neutral pronoun in the same way as the second-person singular. 9 It seems possible to use the anaphoric pronoun "she" with "Penelope" in referring to John. However, we believe that it connotes a critical attitude of the intended referent.

Organon F 28 (1) 2021: 253-268 
pronoun. ${ }^{10}$ However, as mentioned, we do not think that the same thing holds true for metaphorical tokens of the same sentence. In order to preserve the felicity of the metaphor it seems that one must use the pronoun that agrees with the gender of the actual referent. For, it would be infelicitous to misgender the referent (but see footnote 9). In Gricean terminology, the speaker flouts the maxim of quality (truthfulness: do not say what you think to be false), not to mention the sort of disrespect that comes with misgendering.

We think the same thing holds true for utterances where the name is not fictional, but refers to an actual person. Consider the case where your friend, Jane, a renowned physicist has had yet another significant breakthrough in her research. It seems permissible to say:

(6) Einstein ${ }_{1}$ just had another breakthrough; she $e_{1}$ is well on her way to a Nobel prize

In the case of anaphoric descriptions, we seem to have a bit more license. For example, we may extend the metaphor, and say things that apply to Odysseus, and predicate them of Bill. Alternatively, we may also use descriptions that does not fit properties of the metaphorical referent. Consider the following:

(7) Odysseus 1 returned home, [the lazy bastard $]_{1}$ is hungry ${ }^{11}$ where the epithet picks out Bill, and not the mythical Odysseus. In this case the description works like an anti-logophoric pronoun.

So, given our analysis so far, we can identify two ways descriptions can be linked to the metaphorical use of a proper name: (i) the description can convey non-metaphorical information about the referent (which is selected by the metaphorical use of the name), such as (1); or (ii) the description can convey further metaphorical information about the latter, such as (2).

10 We are here assuming that the name "Penelope" marks the gender of the referent and that it is not used like "Sue" in Cash's famous song "A Boy Named Sue".

11 Although we will concentrate on descriptions used anaphorically, we think the same story could be used to analyze complex demonstratives used anaphorically, such as: "Odysseus 1 returned home, [that brave soldier] $]_{1}$ is hungry" or "Odysseus ${ }_{1}$ returned home [that lazy bastard] $]_{1}$ is hungry". 
Consider (7), an utterance used to refer to Bill who has just returned home from a week-long vacation in the Bahamas, where he did nothing but eat, sleep, and drink. Here "Odysseus" is used to refer to Bill, along with the description "the lazy bastard". Although co-referential with the metaphorical use of "Odysseus" the description's primary communicative goal is not to convey a metaphorical interpretation. Rather, the metaphor interpretation serves as a springboard to generate the sarcasm expressed by the speaker. ${ }^{12}$ In Gricean terms, we offer a rational reconstruction of the inferential strategy used by the auditor ${ }^{13}$ : An audience familiar with the Homeric epic would recognize (7) as being odd, given that Odysseus was anything but lazy, let alone a bastard. Rather, (7) communicates the information that "Odysseus", referring to Bill, is uttered sarcastically to set up a contrast between Bill and the fictional Odysseus. In that case, the description works like an anti-logophoric pronoun. We may illustrate a case of (ii) by an utterance such as (2), that we repeat here:

(2) Odysseus ${ }_{1}$ returned home, [the brave soldier $]_{1}$ is hungry

uttered to highlight, for instance, the fact that Bill has been on a long tour in Afghanistan. In that case the metaphorical description "the brave soldier" is used to explicate some feature of Odysseus that gets transferred to and aligned with properties that are true of Bill. The description in (2) pragmatically forces the anaphoric interpretation insofar as it raises to salience some features commonly attributed to the mythical Odysseus that are further aligned with Bill in the mapping process from source to target.

\section{Presuppositions}

When we use proper names, we generally presuppose the existence of the referent to which it refers. However, we have seen that there are

12 Following Stern (2000), and (Popa-Wyatt 2017; Popa-Wyatt 2010) for the logical, and psychological priority of metaphor interpretation in compound figurative utterances (e.g., metaphorical/ironic expression).

13 See Genovesi $(2019,2020)$ for a detailed analysis on the differences between rational interpretation and actual inferential processing.

Organon F 28 (1) 2021: 253-268 
exceptions to this generality. In referring to Bill by using the name "Odysseus", one doesn't interpret this as referring to the fictional character, but rather exploits the name to pick out a property or properties to link it to the intended referent (i.e., Bill). Corazza \& Genovesi (2018) explored how this was possible. In relation to anaphora, the notion of presupposition can help us capture the mechanism by which the anaphora is bound to the intended discourse referent. We follow Stalnaker (1999) in understanding presuppositions to be a pragmatic phenomenon. For the expressions (1) and (2) to be considered appropriate in context, the speaker and auditor mutually know or assume some information. He writes:

Presupposition, as ordinarily understood, is a propositional attitude, and not a semantic relation. It is speakers who make presuppositions; what they presuppose are the things they take for granted when they speak - things they take to go without saying. If this is what presupposition is, then the falsity of something one presupposes will not necessarily be incompatible with the truth or falsity of what one says when making those presuppositions. (Stalnaker 1999, 7)

Furthermore, we know that presuppositions are heritable. They are usually maintained by negatives, interrogatives, and conditional antecedents:

(1) a. Odysseus 1 has returned home, he ${ }_{1}$ is hungry

b. Odysseus 1 has returned home, he is not hungry

c. Odysseus 1 has returned home, is he ${ }_{1}$ hungry?

d. If Odysseus ${ }_{1}$ has returned home, then he must be hungry ${ }^{14}$

Thus, the metaphorical use of "Odysseus" to refer to Bill, like a presupposition, can preserved in negative, interrogative and conditional antecedents as shown above. In other words, when analyzing our target sentences (1) and (2), we must consider the speaker's use of "Odysseus" as intended to refer to Bill as a presumption that the hearer will keep in mind to resolve the anaphoric complement.

The content expressed by metaphorically using "Odysseus" to refer to Bill in (1) is that Bill returned home and that, Bill is hungry. This is,

14 Here the presupposition filtered, but it is not blocked by the conditional. 
roughly, how the metaphorical use of a proper name works together with its anaphoric complement. If this is right, then we know that the function of the MPN is motivated by establishing a connection from Odysseus to Bill. As such, disagreement about whether Bill embodies some or many properties of the mythic hero does not affect the truth-value of the utterance. Rather, what is relevant for the truth-value is whether or not Bill did in fact return home, and whether or not Bill is hungry. ${ }^{15}$

The propositional attitude carried by the anaphoric use of a description like "the brave soldier" in (2) picks up Bill (who is referred to via the use of the fictional name "Odysseus"). In that case the speaker exploits stereotypical information about Odysseus (i.e., that he is a brave soldier) to anaphorically refer back to Bill. By doing so, the speaker makes explicit some descriptive content that is associated with the mythical Odysseus. Typically, in uttering a metaphor, the stereotypical information is not explicit. For example, if one utters "That politician is a snake" one may intend an auditor to come to understand that one means some stereotypical information such as being deceitful or treacherous. However, one could also mean that the politician in question is cunning or that he swallowed a big case, and so on. In order to come to the intended message an auditor has to make explicit for oneself what the speaker means and intends to communicate.

Like with presuppositions, once it is established that Bill is the intended referent the hearer keeps the link between Odysseus and Bill in the background of the discourse situation. This should help us to explain cases such as (2), where the speaker extends the metaphorical link between Bill and Odysseus by using further descriptions concerning Odysseus (in our example "the brave soldier") to anaphorically refer to Bill, while still

15 On this aspect one can subscribe to either the Fregean view that utterances of sentences containing an empty term (like, e.g., a fictional name) lack a truth value or that this utterance is false, as Russell would argue. We remain neutral. Nevertheless, we are sympathetic with the direct reference view (see, e.g., Donnellan 1974) that the tokening of a sentence like "Peter Pan never grows old" does not express a (singular) proposition for the simple reason that there is no object entering the proposition expressed. In our paradigm case the speaker, in exploiting "Odysseus" to refer to Bill, expresses a singular proposition having Bill as a constituent and the latter is true if Bill instantiates the property of having returned home, false otherwise.

Organon F 28 (1) 2021: 253-268 
conveying the main message (i.e., that Bill ${ }_{1}$ has returned home and that he ${ }_{1}$ is hungry). In that case the description used anaphorically brings to salience some stereotypical properties commonly associated with the mythical Odysseus.

An upshot of this account is that it meshes well with the understanding of epithets (cf. Corazza, 2005). Like epithets, the proposition expressed by the attributive anaphora can be cancelled without affecting the truth-value of the utterance. Consider first an epithet from Corazza (2005), then our example (2):

(8) A: Sue told Jon 1 that [the idiot $]_{1}$ should run for president.

B: Actually he's not an idiot. He has a Ph.D. in Political Science.

Now consider:

(9) A: Odysseus 1 has returned home, [the brave soldier $]_{1}$ is hungry.

B: Actually, he hasn't been brave at all, although he was gone for quite a long time.

One question is whether an anti-logophoric pronoun and a metaphorical description used anaphorically behaves similarly when embedded in attitude ascriptions. Consider:

(10) John said that Odysseus 1 returned home and that [the brave soldier $]_{1}$ is hungry

(11) John said that Trump ${ }_{1}$ returned home and that [the dumb racist $]_{1}$ is hungry

Whether the anaphoric epithets "the dumb racist" and the anaphoric description "the brave soldier" attribute to John the use of these words, or these words merely characterize the narrator's attitude and, as such, scope out of the attitude ascription is, no doubt, an open question. We will not deal with it here but wish to mention it if only to bracket it for later analysis. Nonetheless, we think that whatever the answer one gives one ought to consider (10) and (11) on par, insofar as they seem to behave similarly. On our estimation, a name used metaphorically seems to play two roles. First, it allows discourse participants to pick out the referent the speaker has in mind. Second, it allows the audience to apply some properties normally attributed to the character evoked by the metaphorical term, to 
the referent the speaker has in mind. When an anaphoric pronoun is linked to a name used metaphorically it seems to respect and preserve this dual role. The link in this case is not syntactic (we often face cases of so-called trans-sentential anaphora like "she" in "Maryı won the lottery. She is now rich"). One way to deal with such cases would be to follow Lasnick (1976) and Kripke (1977), in arguing that the anaphoric pronoun can be understood to work as a demonstrative picking out the object previously raised to salience in the discourse situation. In this case, the co-referential link is pragmatically driven and guided by some considerations of the discourse context.

\section{Conclusion}

This paper dealt with a specific type of metaphor where a proper name is used metaphorically to determine the referent of the expression. In tandem with previous work on MPNs, this paper serves to generate discussion on how MPN expressions behave in wider linguistic contexts, specifically with anaphoric pronouns, and descriptions. Our aim was modest. We raised issues about MPNs and anaphoric clauses precisely because proper names and metaphors have independently raised interest in a wide variety of academic disciplines. We have provided some cursory observations on the usefulness of various other linguistic phenomena such as anti-logophoricity and presupposition. We hope such observations to aid in further analysis of MPNs and their anaphoric clauses in future works. In general, we hope to have brought forward how various uses of language in everyday linguistic interactions allow us to convey information that is not directly encapsulated in the semantic and syntactic profile of the sentence uttered. From a formal viewpoint, it remains an open question to spell out how our discussion and insights therein can be represented. One promising area of exploration is to consider the sort of model that is used in the retrieval of metaphorical meaning of the proper name. Currently, there is a debate concerning categorization models and property-transfer models. Briefly, the former argues that metaphors construct an ad hoc category, which assigns the topic to a category specified by the vehicle. In our paradigm case, Bill belongs to a 
category of something like HOMECOMING MEN, specified by the source, Odysseus. The latter specify the transfer of attributes from the source, Odysseus, such as homecoming, brave, arduous journey, to the target, Bill. ${ }^{16}$ We are positive that adjudicating between these models can fruitfully inform a theory of MPNs in wider linguistic contexts. Be it as it may be, the authors think that the phenomenon of MPNs and anaphora discussed in this paper ought to be considered when thinking about a comprehensive theory of proper names and metaphor.

\section{Funding}

Eros Corazza: The research is sponsored by the Spanish ministry of economics and competitivity (FFI2015-63719-P (MINECO/FEDER, UE); The Ministry of Science and Innovation of the Spanish Government (PID2019-106078GB-I00/AEI /10.13039/501100011033); the Basque Government (IT1032-16).

Chris Genovesi: The research is supported in part by The Ministry of Science and Innovation of the Spanish Government (PID2019-106078GB-I00/AEI/ 10.13039/501100011033); and funding from the Social Sciences and Humanities Research Council (756-2019-0813).

\section{References}

Bambini, Valentina; Ghio, Martha; Moro, Andrea, \& Schumacher, Petra B. 2013. "Differentiating Among pragmatic Uses of words Through Timed Sensicality Judgments." Frontiers in Psychology 1-16. https://doi.org/10.3389/fpsyg.2013.00938

Cacciari, Cristina \& Glucksberg, Sam. 1994. "Understanding Figurative Language." In Handbook of Psycholinguistics, edited by Morton Grensbacher, 44777. New York Academic Press.

Camp, Elisabeth. 2009. "Metaphor." In The Pragmatics Encylopedia, edited by Louise Cummings, 264-66. Routledge.

Corazza, Eros. 2005. "On Epithets qua Attributive Anaphors." Journal of Linguistics 41 (1): 1-32. https://doi.org/10.1017/S0022226704003044

16 See Ritchie (2013) for a good introduction to this debate. See Wee (2006) for a view that defends MPNs as involving categorization. 
Corazza, Eros \& Genovesi, Christopher. 2018. "On the Metaphoric Use of (Fictional) Proper Names." In Objects of Inquiry in Philosophy of Language and Linguistics, edited by Piotr Stalmaszczyk, 41-58. Peter Lang.

Donnellan, Keith. 1974. "Speaking of Nothing." The Philosophical Review 83: 3-31. https://doi.org/10.2307/2183871

Dubinsky, Stanley \& Hamilton, Robert. 1998. "Epithets as Anti-Logophoric Pronouns." Linguistic Inquiry 29: 685-93.

Genovesi, Christopher. 2018. "What Is Not Said: Metaphor and the Deflationary Account." Studies in Applied Philosophy, Epistemology and Rational Ethics (Vol. 42). https://doi.org/10.1007/978-3-319-91277-6_3

Genovesi, Christopher. 2019. Food for Thought: Metaphor in Communication and Cognition. Carleton University.

Genovesi, Christopher. 2020. "Metaphor and What is Meant: Metaphorical Content, What Is Said, and Contextualism." Journal of Pragmatics 157: 17-38.

Glucksberg, Sam \& Keysar, Boaz. 1990. "Understanding Metaphorical Comparisons: Beyond Similarity." Psychological Review 97 (1): 3-18.

https://doi.org/10.1037/0033-295X.97.1.3

Hagège, Claude. 1974. "Les Pronoms Logophoriques." Bulletin de La Société de Linguistique de Paris 69: 287-310.

Kripke, Saul. 1977. "Speaker's Reference and Semantic Reference." Midwest Studies in Philosophy 1: 255-76.

Lasnik, Howard. 2001. "Remarks on Coreference." Linguistic Analysis 2, 1-22.

Leezenberg, Michiel. 2001. Contexts of Metaphor. Elsevier.

Popa-Wyatt, Mihaela. 2017. "Compound Figures: Priority and Speech-Act Structure." Philosophical Studies 174 (1): 141-61. https://doi.org/10.1007/s11098016-0629-z

Popa, Mihaela. 2010. "Ironic Metaphor Interpretation." Toronto Working Papers in Linguistics 33: 1-17.

Ritchie, L. David. 2013. Metaphor. Cambridge University Press.

Stalnaker, Robert C. 1999. Context and Content. Oxford, UK: Oxford University Press.

Stern, Josef. 2000. Metaphor in Context. Cambridge, MA: MIT Press.

Wee, Lionel. 2006. "Proper Names and the Theory of Metaphor." Journal of Linguistics 42 (2): 355-71. 